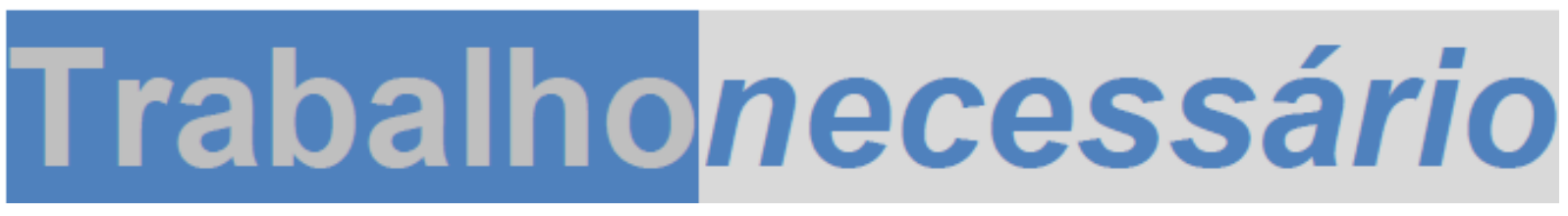

\author{
Issn: 1808 - 799X \\ ano 10, no $15-2012$
}

\title{
UN DEBATE TEÓRICO DESDE MÉXICO SOBRE LA TEORÍA DEL VALOR-TRABAJO Y SU ARTICULACIÓN CON EL TRABAJO DOCENTE DE LA ESCUELA PRIMARIA
}

\author{
María Del Carmen Montero Tirado ${ }^{1}$
}

\begin{abstract}
Introducción.
\end{abstract}
..........El presente Ensayo es fruto de una investigación de aproximadamente 3 años de trabajo intenso y finalizó con la publicación del Libro ¿Es el Trabajo Docente una Profesión o es la Profesión Docente un Trabajo? Trabajo y Profesión Docente de los Profesores de la Escuela Primaria Publica en México, editado por la Universidad Pedagógica Nacional en la Ciudad de México en diciembre de 2007. Entre las experiencias más significativas obtenidas fue el haber incursionado en una interesante e importante discusión sobre la complejidad del trabajo y especialmente intentar poner en claro hasta dónde el trabajo docente es un trabajo productivo desde la perspectiva de la teoría del valor trabajo. Esta desde nuestro punto de vista y del de otros estudiosos del tema dicha discusión, no ha sido superada y no ha habido otra teoría que nos explique el origen del capital, explicando el trabajo y el desarrollo económico en toda su dimensión histórica, económica, política y social, como lo ha efectuado la propuesta marxista. En este sentido, tratamos de destacar la importancia del trabajo y su contenido

\footnotetext{
${ }^{1}$ Doctora en Sociología Egresada de la Universidad Nacional Autónoma de México y Profesora e Investigadora de la Universidad Pedagógica Nacional - Ajusco. Miembro del Área de Diversidad e Interculturalidad. Mail: monterotir@yahoo.com.mx mmontero@upn.mx
} 


\section{Trabalhonecessário}

Issn: 1808 - 799X

ano $10, \mathrm{n}=15-2012$

multidimensional y polisémico. El trabajo es una actividad esencial en la historia de la humanidad, es una fuerza creadora, transformadora y heterogénea; según desde el ángulo de lectura que se quiera estudiar y la etapa histórica y concepción de teoría social que se considere. E incluso llegamos a la conclusión que el trabajo es una construcción social y hasta cierto punto difusa e ininteligible. Es por esto que nos sentimos profundamente satisfechos de haber participado en una discusión inacabada y esperamos haber contribuido en este debate, tratando de precisar tanto la naturaleza del trabajo en sí mismo, como la del trabajo docente y su trascendencia económica y social. Y retomamos la teoría del valor trabajo porque es esta la que deja en claro que la ganancia es la esencia de la economía capitalista y a su vez el origen de esta radica en el trabajo, siendo este visto como una mercancía mas y ocultando la apropiación de un trabajo excedente. A continuación se expone ampliamente esta teoría.

\section{Fundamentación Teórica del Trabajo como Valor y el Trabajo Docente.}

La importancia de la teoría del trabajo como valor tiene su origen en la segunda mitad del siglo XIX por David Ricardo, uno de los teóricos clásicos más importante de la economía política (siendo esta dominante en las ciencias sociales), quien menciona en su crítica a la economía política la importancia del trabajo como vital para explicar el principio del valor como generador de la riqueza social. Al respecto Enrique de la Garza recuperando esta propuesta destaca:

(...) el concepto de trabajo fue central, y fue entendido sobre todo como el creador de valor (Ricardo, 1862). Los clásicos definieron el campo de la economía como el estudio de la creación de la riqueza, y ésta estaba en función del trabajo incorporado en las mercancías. La utilidad, como satisfacción subjetiva de la mercancía, como valor de uso, 


\section{Trabalhonecessário}

Issn: $1808-799 X$

ano 10, no $15-2012$

fue considerada, pero lo central era el proceso de producción, no la circulación o el consumo. $^{2}$

Sin embargo, el valor del trabajo o el trabajo como valor se modifica a lo largo de la historia acorde a la ideología hegemónica dominante: en las ciudades griegas de la época clásica; en el feudalismo medieval en Occidente, el trabajo (las tareas manuales de acción sobre la naturaleza), no eran estimadas como valores, por el contrario, como actividades relegadas a las clases inferiores. En la URSS, en cambio, se enfatizaba el reconocimiento del valor en sí del trabajo manual: era cuestión de honor, valentía, y heroísmo ${ }^{3}$. En este sentido podemos pensar que el valor del trabajo docente, como dice Martínez Bonafé, radica en ver el valor de uso de la fuerza de trabajo de los profesores, no desde el orden ideado, abstraído de toda forma histórica y de toda concreción social, sino desde el orden impuesto ${ }^{4}$. Es decir, de acuerdo a la división social del trabajo, en el que el trabajo docente juega un papel de suma importancia contribuyendo a la generación de una mercancía llamada conocimiento, que bien puede agregar valor a otras mercancías, o bien dicho, conocimiento puede generar nuevas mercancías para el capital.

Si bien existe un carácter útil del trabajo que produce mercancías, bienes o servicios, lo que subyace en esencia es el trabajo humano, consumo de fuerza de trabajo, representado mediante un producto o mercancía, en la que se contiene determinada cantidad de trabajo, que abarca desde un trabajo simple hasta un trabajo complejo. En el caso de la fuerza de trabajo de los docentes (...) 


\section{Trabalhonecessário}

Issn: 1808 - 799X

ano $10, \mathrm{n}=15-2012$

el consumo cultural se incorpora a la mercancía fuerza de trabajo, lo que está produciendo no es simple intercambio, sino un proceso productivo en el que los conocimientos actúan como simple medio de producción para la fabricación y calificación de esa fuerza de trabajo. ${ }^{5}$ Un ejemplo de esto puede ser desde la formación de técnicos e ingenieros que están para la incursión directa en la producción, hasta la propia formación de profesores, quienes a su vez están capacitando y formando mano de obra, para el mercado de trabajo. La teoría del capital humano es una respuesta a esto.

Pero ¿por qué se habla del trabajo como valor?, ¿tiene cualidades y atributos intangibles? El trabajo es un valor que posee esencialmente el atributo de ser una utilidad para satisfacer necesidades y proporcionar bienes, además de proporcionar el propio desarrollo humano. En este sentido, la concepción del trabajo como valor y su proceso transformador es una perspectiva fundamentalmente marxista con una visión creadora, transformadora, que no solo destaca la utilidad e importancia del trabajo humano, sino también su trascendencia social. Esto podría explicar porque Marx en toda su teoría desarrolló no solo la importancia del trabajo humano sino que fue más allá al presentarnos su noción de fuerza de trabajo y destacó la forma minuciosa, la forma como se genera el trabajo en forma intrínseca en el hombre en lo individual hasta la construcción del trabajo colectivo, veamos a continuación lo expuesto directamente por Marx:

(...) el individuo no puede operar sobre la naturaleza sin poner en acción sus propios músculos, bajo el control de su propio cerebro. Así como el sistema natural de su cabeza y la mano forman un conjunto, el proceso laboral unifica el trabajo de la mente y el de la mano. Más tarde uno y otro se separa hasta conformar una antítesis radical. El productor 


\section{Trabalhonecessário}

Issn: 1808 - 799X

ano 10, no $15-2012$

individual, se transforma en general en el productor colectivo de un personal combinado de trabajo, cuyos miembros están más cerca o más lejos del manejo del objeto de trabajo. Al ampliarse el carácter cooperativo del proceso laboral mismo, se amplía necesariamente, por consiguiente, el concepto de trabajo productivo y de su portador, el obrero productivo (..... $)^{6}$.

Esto muestra la importancia del trabajo humano en la concepción marxista y porqué el trabajo es un valor, además de la existencia del trabajo colectivo, cooperativo, que es decisivo para la existencia del trabajo productivo y con ello la existencia del obrero mismo; hay una relación entre la actividad del obrero y su efecto útil generado por el producto de su trabajo que a su vez constituye una relación de producción social, así, el trabajador se convierte en un medio directo para la valorización del capital por lo que el obrero no produce para él mismo en forma individual, sino para el proceso de producción capitalista. Así desde la perspectiva marxista, el uso del trabajo humano no solo produce mercancías para el capital en forma llana, sino que a su vez está produciendo un excedente para este, y también dicho trabajo está generando las condiciones para su reproducción. Veamos la forma en que nos lo expone Marx.

(...) el valor de la fuerza de trabajo, o sea el tiempo de trabajo requerido para su producción, determina el tiempo de su trabajo necesario para la reproducción de su valor. Si una hora de trabajo representa en una cantidad de oro de medio chelín (...) el valor diario de la fuerza de trabajo asciende a 5 chelines, el obrero tendrá que trabajar diariamente 10 horas para reponer el valor diario de su fuerza de trabajo, que le ha abonado el capital, o sea para producir un equivalente del valor de los medios de subsistencia que necesita día a día (...).

Sin embargo, el valor de una mercancía no se determina solamente por la cantidad de trabajo, sino también por la masa de trabajo contenida en sus medios de producción; el valor de la fuerza de trabajo está determinado por el valor de los 


\section{Trabalhonecessário}

Issn: 1808 - 799X

ano 10, no $15-2012$

medios de manutención. En palabras de Marx, (citando a William Petty), el valor del jornal medio se determina por lo que el obrero necesita para vivir, trabajar y procrear [el] precio del trabajo está constituido siempre por el precio de los medios de subsistencia imprescindibles ${ }^{8}$, o lo que es lo mismo, el valor de la fuerza de trabajo se determina por el tiempo de su trabajo necesario para la reproducción de su valor. Lo importante es observar la relación entre el obrero y quien se apropia del producto de su trabajo, como una relación fundamentalmente social que coloca al trabajador a modo productor de plusvalor y lo constituye en elemento clave del proceso de valorización del capital, de ahí que para la lógica del capitalista sólo es productivo aquel trabajador que produce plus valor, y no ve los otros factores que inciden en el proceso de producción.

El plusvalor es un valor adicional al valor que en sí requiere la fuerza de trabajo para su reproducción (...) la magnitud del plustrabajo se obtiene sustrayendo de la jornada laboral total el tiempo de trabajo necesario [para la producción de mercancías, y la reproducción de la fuerza de trabajo](...) o sea que una cantidad menor de trabajo adquiera la capacidad de producir una cantidad mayor de valor de uso(...) $)^{9}$. Este proceso de creación de plusvalor se logra por el incremento de las fuerzas productivas, e implica una revolución en las técnicas y condiciones de producción que buscan emplear el menor número de trabajadores (capital variable) y una menor cantidad de tiempo mano de obra, para que una empresa reduzca gastos de producción y buscar un avance tecnológico de la misma. Esto a su vez genera una crisis en el sistema capitalista, la burguesía en su afán de incrementar la cuota de ganancia y de disminuir el costo de mano de 


\section{Trabalhonecessário}

Issn: 1808 - 799X

ano $10, \mathrm{n} \times 15-2012$

obra, genera una angosta base de consumo que impide la realización de las mercancías.

En esta forma, se entiende que el plusvalor y el plustrabajo son parte del mismo fenómeno y se expresan así: (...) la línea a_c, esto es, a_b_c, representan una jornada laboral de 12 horas; en el segmento $a \_b=10$ horas de trabajo necesario, el segmento b_c $c=2$ horas de plustrabajo. Ahora bien, ¿cómo se puede aumentar la producción de plusvalor, esto es, el plustrabajo, sin ninguna prolongación ulterior de a_c?(...). ${ }^{10}$ Esto se logra con el mejoramiento de la maquinaria, equipo y con una modificación en la organización del trabajo, lo que permite reducir las horas de trabajo del segmento $a \_b$ de 10 horas, por ejemplo a 8; y el segmento b__ c aumenta de 2 a 4 horas, y con esto se incrementa la producción de plusvalor, manteniéndose al mismo tiempo la jornada laboral de 12 horas.

Este fenómeno permite la creación del plusvalor absoluto y plusvalor relativo, ambos se presentan como tipos de producción diferentes pertenecientes a diferentes épocas de desarrollo de capital. Por ejemplo,

(...) la producción de plusvalor absoluto trae aparejado que las condiciones de trabajo, propias de cosas, se transformen en capital y los trabajadores en obreros asalariados; que los productos sean producidos en cuanto mercancías, esto es, producidos para la venta; que en el proceso de producción sea al propio tiempo proceso en que el capital consume la fuerza de trabajo, y por tanto esté sometido al control de los capitalistas; finalmente, que se prolongue el proceso de trabajo, $y$ 


\section{Trabalhonecessário}

Issn: 1808 - 799X

ano 10, no $15-2012$

por tanto la jornada laboral, más allá del punto en que el obrero sólo ha producido un equivalente por su fuerza de trabajo(...). ${ }^{11}$

Mientras que por el contrario el plus valor relativo (...) es la reducción del tiempo de trabajo necesario y del consiguiente cambio en la proporción de magnitud que media entre ambas partes [tiempo de trabajo necesario y excedente] componentes de la jornada laboral (...... ${ }^{12}$. De esta forma, se nota cómo el proceso histórico de intervención del capital genera una metamorfosis en la que el plusvalor absoluto tiende a transformarse en una forma de extracción de plusvalor relativo, y, en ambos, aparece simplemente la venta "voluntaria"13 de la fuerza de trabajo por la que se da un pago (conocido como salario), por el tiempo de trabajo contratado, sin dar cuenta del proceso de extracción de valor que implica el trabajo a lo largo de su existencia, al menos bajo el sistema de producción capitalista.

Analizar al trabajo docente desde la concepción de la teoría del valor resulta ser un tanto arriesgado, pero en ésta tarea encontramos a serios profesionales como a Martínez Bonafé quien destaca que:

(...) lo que hace una maestra todos los días, desde que entra en el colegio, es trabajo. $Y$ lo que hizo al firmar su contrato de trabajo con el empleador, ya sea privado o estatal- es vender su fuerza de trabajo, su capacidad para desarrollar el trabajo productivo de enseñar. La vende a cambio de un salario en sus diferentes formas, no sólo monetarias. Así, el trabajo de la maestra es la actividad en la que se consume esa capacidad de desarrollar ese trabajo productivo de enseñar, en la que se consume la mercancía fuerza de trabajo ${ }^{14}$.

Esto significa que los conocimientos son utilizados por el Estado, ya que controla los niveles educativos básicos, como una mercancía que no corresponde al proceso productivo de una fábrica, sino que es utilizada para formar a otros 


\section{Trabalhonecessário}

Issn: 1808 - 799X

ano $10, \mathrm{n}=15-2012$

seres humanos que probablemente se integren, cuando alcancen la mayoría de edad, a los procesos productivos de los empresarios.

Sin embargo, Noam Chomsky y Heinz Dieterich en el capítulo "El deseo terrible de emplearse" señalan que (...) es el subempleo de la fuerza laboral el que explica la pobreza generalizada de América Latina, a tal grado que John Well, especialista de la OIT sostiene que el principal factor en la región es 'la potencia de altas tasas de subempleo en la región ${ }^{15}$.

El tiempo de trabajo es la fuente del valor, pero trabajo social y no individualizado como trabajo socialmente necesario, es decir tiempo requerido históricamente para producir una determinada mercancía (manteniendo constantes los otros elementos, tales como la dotación de materias primas y de medios de producción, la calidad, etc. ${ }^{16}$. Un bien entonces tiene valor porque en él está objetivado o materializado un trabajo humano que se puede medir por la cantidad de trabajo contenida en el bien, y se expresa en términos temporales: como la hora, el día, la semana, el mes. Concebida así, la fuerza de trabajo, en cualquiera de sus modalidades, es la fuente de valor y generadora de riqueza; el salario pagado por el empleador sólo paga el trabajo necesario para la reproducción del trabajador como fuerza de trabajo, y no remunera el valor del trabajo excedente realizado.

Esto permite plantear la existencia de la fuerza de trabajo como mercancía productora al mismo tiempo de mercancías, sólo que la fuerza de trabajo es una mercancía peculiar y superior a las demás, porque contiene un valor superior al que le es remunerado. Por otra parte, la fuerza de trabajo, en la medida en que es 


\section{Trabalhonecessário}

Issn: 1808 - 799X

ano $10, \mathrm{n}=15-2012$

un valor, sólo existe como facultad del individuo vivo que requiere de medios de subsistencia necesarios para su conservación y reproducción como mercancía.

El trabajo de la enseñanza o trabajo docente es una mercancía y tiene valor porque se le incorpora, en el proceso de producción, la mercancía fuerza de trabajo. En otras palabras, agrega Martínez Bonafé:

(...) el valor de cambio de fuerza de trabajo de una maestra en el mercado de trabajo es el valor de lo que le ha sido añadido a su energía vital humana, lo que ha cualificado esa energía vital, dándole la posibilidad de ejercer una tarea específica porque ha adquirido los conocimientos y destrezas necesarios para desarrollarla. Claro que en realidad, la posibilidad del valor- es de uso y de cambio-está relación directa con su inclusión en el proceso productivo. Si no hay mercado, no hay valor, como saben y pasan a engrosar las listas de los desocupados ${ }^{17}$.

Porque el valor de la fuerza de trabajo en el proceso de producción está condicionado en la medida que el mercado demande de ella, por ejemplo, la modernización económica que trastoca al sistema educativo, influyendo en el valor de cambio de la fuerza de trabajo docente, éste varía en relación directa a su sujeción, a las directrices del Estado; en el caso de México la Carrera Magisterial. La fuerza de trabajo es imputable al trabajo humano (desgaste físico y orgánico). El propietario de esta fuerza debe tener las mismas condiciones de salud y energía para repetir la operación del trabajo requerida durante su tiempo de contratación, lo que demanda obtener los medios de subsistencia necesarios para su reproducción. El trabajo individual en sí mismo carece de sentido si no está en función del colectivo del que forma parte; dado en función del colectivo, la tarea se le asigna y, a su vez, está condicionada por el trabajo de otros, al mismo tiempo que su tarea en lo individual ejercerá influencia sobre la tarea de los demás 


\section{Trabalhonecessário}

Issn: 1808 - 799X

ano 10, no $15-2012$

miembros del colectivo. Esto conlleva a la existencia una cooperación simple y compleja en la realización del trabajo, o de una división del mismo.

Es decir, para producir valores de uso diferentes (mercancías o bienes), se requieren trabajos cualitativamente diferentes, para que los productos, bienes y mercancías puedan intercambiarse. Así, la división social del trabajo constituye una condición para la existencia de la misma producción de mercancías; estas mercancías de igual forma generan competencia entre ellas, como expresión de las relaciones sociales de producción, porque encierran en sí mismas trabajos útiles cualitativamente diferentes. Simultáneamente, todas las mercancías (productos y bienes) por ser valores de uso y de cambio, igual que el trabajo (como mercancía fuerza de trabajo que se vende), se convierten en una medida colectiva de valor: [el] dinero es así la forma de manifestación necesaria de la medida de valor inmanente a las mercancías: tiempo de trabajo. El precio [será] entonces la denominación dineraria del trabajo objetivado en la mercancía (....). ${ }^{18}$

El trabajo como valor. Se denota que no todo trabajo es productivo, generador directo de plusvalor, sino que hay un trabajo improductivo, que no incide de manera directa en la creación de valor para la reproducción, expansión y acumulación del capital. Bajo esta lógica, el trabajo de servicios es improductivo, incluido el trabajo docente objeto de esta investigación, sin embargo, el trabajo del maestro contribuye a la reproducción del capital, es decir, al proceso de valorización de éste; en tanto que capacita a la mano de obra para el trabajo e incrementa su productividad, porque la adiestra y prepara para generar más valor en la producción de mercancías y garantizar la acumulación de capital; aún cuando la incorporación de valor de la fuerza de trabajo esté condicionada por el 


\section{Trabalhonecessário}

Issn: 1808 - 799X

ano $10, \mathrm{n} \times 15-2012$

mercado de trabajo. En el siguiente apartado de este capítulo se expondrá esta discusión teórica.

De aquí la inquietud de estudiar el trabajo desde la perspectiva de la teoría del valor expuesta por Marx, y reconocer con las herramientas teóricas que esta propuesta nos brinda, la trascendencia del trabajo docente en la escuela primaria pública, que además de capacitar y habilitar a la fuerza de trabajo, tiene una función más amplia en el contexto económico, social y cultural, como la formación de valores, actitudes y destrezas en un ramo laboral determinado y que se convierte en una fuerza de trabajo productiva. Más aún, el reconocimiento de papel del hombre en la construcción de su propia historia a través del trabajo. Sin embargo, contrariamente a la importancia del trabajo docente, la remuneración de los maestros es insuficiente para obtener su reproducción diaria como fuerza de trabajo y satisfacer necesidades de subsistencia, recreación, procreación, y sustitución de fuerza de trabajo vieja por nueva.

Esta realidad del trabajo docente es contradictoria porque, por otro lado, se presentan nuevas exigencias al trabajo de enseñanza, tales como la intensificación del trabajo; diversificación de tareas y una mayor tensión por cumplir con todos los requerimientos que demanda el proceso de modernización educativa; generando en el maestro un desgaste de energía física y mental, así como una nueva cultura social, laboral, entre otras exigencias, que no son recompensadas a través del salario que perciben.

También existe el trabajo extraordinario, considerado, generalmente, como trabajo improductivo, por el carácter de actividades que se realizan en el tiempo libre (utilizado por los trabajadores para su descanso y recreación) que influyen 


\section{Trabalhonecessário}

Issn: 1808 - 799X

ano $10, \mathrm{n}=15-2012$

para la realización de la producción ${ }^{19}$ como actividades profesionales: capacitación en horarios fuera de la jornada; incluso, en días de descanso, vacaciones que no cuentan con pago alguno: factor común en el trabajo docente.

En la educación primaria pública en el Distrito Federal hay cursos que paga la institución al inicio del ciclo escolar, y otros que no son pagados por ninguna autoridad educativa y que son importantes para que los profesores puedan calificar en la Carrera Magisterial. Ambos cursos permiten a los maestros acceder a un estímulo salarial, y también ser trabajadores productivos de acuerdo a los requerimientos institucionales, y con esto logran producir a la vez una mayor cuota de plus valor.

\section{El Trabajo Docente desde la Propuesta de la Teoría Del Valor-Trabajo.}

La recuperación de la categoría de trabajo desde la perspectiva de la teoría implica, analizar el carácter del trabajo docente en la educación primaria desde una perspectiva crítica expuesta en la teoría del valor trabajo. Esto significa trascender y no quedarnos con la noción elemental que la labor de la enseñanza es un empleo más ubicado en el sector de servicios ${ }^{20}$, o bien que es una actividad terciaria, o menos aún que el trabajo de la enseñanza es una simple actividad laboral; o lo que es lo mismo, es simplemente una ocupación más, entre otras. La propuesta radica en plantear que el trabajo, pensado como una categoría de análisis desde la concepción marxista, expresa una determinación general de formas de vida abstractas vinculadas a la realidad, con una visión totalizadora y ver su relación interna con el todo social. Desde esta perspectiva podemos 


\section{Trabalhonecessário}

Issn: 1808 - 799X

ano $10, \mathrm{n}=15-2012$

analizar el papel que juega el trabajo docente de la educación primaria, dentro de la sociedad en su conjunto, y en particular en el proceso de producción capitalista.

Esta propuesta es trascendental porque se rechaza la idea de entender al trabajo de la enseñanza únicamente como una actividad laboral o empleo, incluido en el mercado laboral dentro del sector servicios, como cualesquier otro empleo; se ha dejado de lado la importancia de esta labor como actividad profesional, que es necesaria en el proceso de producción capitalista y que participa en el proceso de valorización y en la reproducción del capital, a través de la formación de habilidades y destrezas (hoy llamadas competencias) para la inserción de la mano de obra en el mercado de trabajo.

Esta discusión no es fácil de argumentar; encierra una polémica compleja y controvertida, en la que no basta efectuar la lectura del Capital de Marx, sino que es indispensable conocer otras obras como la del VI Inédito, La Ideología Alemana, Introducción a la Crítica de la Economía Política, por citar algunas, así como la propuesta sobre el Trabajo docente que efectúan Bonafé, y Frigotto, SMYTH, et. al y Salinas e Imaz, fundamentalmente ${ }^{21}$.

Con las propuestas de estos autores y con las herramientas de análisis de la teoría marxista; nos proponemos poner a discusión nuestra propuesta de considerar al trabajo del maestro de la escuela primaria como un trabajo que incide en el proceso de valorización del capital, que añade valor a las mercancías en el proceso de producción y reproducción capitalista, a través de los conocimientos, destrezas, etc., que los maestros desarrollan en los alumnos posibilita la incorporación de nuevos elementos a la mercancía 


\section{Trabalhonecessário}

Issn: 1808 - 799X

ano $10, \mathrm{n}=15-2012$

fuerza de trabajo que le permitirán a ésta tener un mejor desempeño en la producción así como una mejor calificación laboral. Esto es también lo que llama Martínez Bonafé el consumo cultural como un medio que propicia conocimientos que actúan a manera de medio de producción, viabilizando la fabricación de otras mercancías. Consideramos que todo éste proceso se da independientemente del papel que juega el trabajo de la enseñanza en la división social del trabajo, es decir, la legitimación de conocimientos y saberes.

A este respecto, lo que se da en la escuela con la actividad laboral desarrollada por los maestros -de una institución privada o estatal- es de alguna forma la realización de un proceso de producción que genera una mercancía intangible denominada conocimientos, destrezas, habilidades, capacitación, etcétera. Estos factores son un medio para producción o fabricación de mercancías, y para la calificación de la fuerza de trabajo. En ambos casos, estos elementos son sustancialmente diferentes a su vez igualmente consumidos por el mercado capitalista, a modo de consumo cultural.

En este sentido, señala Martínez Bonafé, que el trabajo de la enseñanza ejercido por los maestros (...) interviene en el proceso de producción en un nivel determinado dentro de un conjunto de los diferentes y desiguales planos por los que atraviesa el proceso. $Y$ su inclusión en uno u otro plano, viene determinado por el valor de uso y valor de cambio. Pero ese valor se define en todo caso por el nivel en que se sitúa el plano de intervención en la estructura total del proceso, y en ese sentido se oferta y se demanda trabajo; nunca por una supuesta voluntad autónoma o de valoración profesional y social (..... ${ }^{22}$ 


\section{Trabalhonecessário}

Issn: 1808 - 799X

ano $10, \mathrm{n}=15-2012$

Queremos resaltar lo expuesto por el autor en relación a los mencionados diferentes y desiguales planos por los que atraviesa el proceso, y su inclusión en uno u otro plano están determinados por el valor de uso, en tanto que es un trabajo requerido por el mercado, como mano de obra para la realización de una tarea específica, la enseñanza y valor de cambio porque implica la venta de su fuerza de trabajo (traducida en desgaste de nervios y músculos) por dinero: por un salario.

Otro factor en el trabajo son las labores extra-enseñanza que están fuera del trabajo oficialmente reconocido y remunerado, y aparecen como que estuviera fuera del proceso de producción del trabajo que realiza el maestro, quien participa diariamente formando destrezas, habilidades, actitudes para el trabajo de la mano de obra; es decir, los profesores diariamente desde que entran a la escuela hasta que salen, suelen llevar trabajo del plantel escolar a su casa (calificación, evaluación global del ciclo escolar, pasar calificaciones a boletas, preparar material para clases, etcétera), efectuando así un trabajo extraordinario como labor no remunerada, porque parece no ser parte del proceso productivo que ejecutan o de la jornada laboral por la que fueron contratados. A final de cuentas, es trabajo que añade valor e incide en el proceso de valorización del capital en general para la reproducción del sistema capitalista.

La labor del maestro es una actividad que genera la capacidad de desarrollar trabajo en la producción de mercancías tangibles (determinados productos), e intangibles (servicios); que implica consumo de la mercancía -fuerza de trabajo del maestro-, que es vendida a cambio de un salario, del tal forma que el trabajo en sí como actividad es apropiado por quien la compra en el mercado, pertenece finalmente al capital. 


\section{Trabalhonecessário}

Issn: 1808 - 799X

ano $10, \mathrm{n}=15-2012$

En otras palabras, en el mundo mercantil la fuerza de trabajo del maestro adquiere la forma de una mercancía en tanto que su conocimiento calificado, su saber hacer, es lo que le permite asumir al docente un quehacer en la institución escolar. A su vez, esto tiene un valor de uso para quien la compra, ya sea una escuela pública o privada (institución que a su vez evalúa la fuerza de trabajo). De acuerdo a lo expuesto por Marx, es la sociedad capitalista quien consume productivamente el trabajo concreto y calificado a cambio de un salario, y en ese sentido perpetúa su reproducción.

Esta realidad se explica a la luz del esquema de producción de la sociedad capitalista, en la que la fuerza de trabajo se compra y se vende como una mercancía más, operando la misma ley del mercado que hay para todas las mercancías, sólo que en el caso del maestro es peculiar, pues lo que se obtiene de su trabajo como producto es un alumno calificado, su trabajo no es tangible en el corto plazo. Martínez Bonafé retoma a Marx y señal que se genera en

(...) un proceso de enajenación, por el que la energía vital y la adquisición de las competencias que la cualifica [la actividad docente] adquiere valor de cambio, sitúa el denominado perfil profesional en términos de los intereses y necesidades de quien compra esa mercancía fuerza de trabajo (...)[que a su vez] no puede separarse de sus propietarios y sólo puede ser puesta en movimiento por [éstos](...). ${ }^{23}$

Lo expuesto muestra la complejidad del trabajo de la enseñanza, al que no se le debe calificar simplemente como un trabajo improductivo, porque directamente no está implicado en la producción de plus valor, pero que atraviesa por el proceso de enajenación como una mercancía más, que en la medida en que se adecua mejor a los requerimientos del mercado, está en mejores condiciones para ser consumida en ese sentido, es una mercancía cuyo valor de uso si se 


\section{Trabalhonecessário}

Issn: 1808 - 799X

ano $10, \mathrm{n}=15-2012$

relaciona relativamente con su valor de cambio. Esto explica en buena medida las políticas de profesionalización docente y las añoranzas del propio maestro por demandar una mayor capacitación, porque entre más competencias demuestren y cuenten con una mayor certificación, mejor podrá ofrecer su trabajo al mercado en espera de una remuneración superior.

Así se plantea que la actividad de la enseñanza es un trabajo incorporado a la sociedad capitalista como mercancía fuerza de trabajo, que ésta actividad implica gasto de energía humana (cerebro, nervios, músculos, etcétera); y conlleva a la vez un trabajo abstracto y concreto (creando mano de obra), contribuyendo a formar el valor de las mercancías, que será incorporado en el proceso de producción. El valor de uso y el valor de cambio de la fuerza de trabajo del maestro como mercancía está dado por su inclusión en el proceso productivo en general del capital; pero dentro del plano de la producción de conocimiento (formación de habilidades destrezas) y no propiamente dentro del plano de la producción de mercancías tangibles, pensadas como la única producción existente.

Nuevamente Martínez Bonafé explica que (...) el valor de cambio de la fuerza de trabajo de una maestra en el mercado de trabajo es el valor de lo que ha sido añadido a su energía vital humana, lo que ha cualificado esa energía vital, dándole la posibilidad de ejercer una tarea específica porque ha adquirido conocimientos y destrezas necesarios para desarrollarla(...). ${ }^{24}$ La reflexión es importante, porque la educación es necesaria en el desarrollo de la sociedad capitalista, y para satisfacer esta necesidad es imprescindible el trabajo calificado que ejecuta el maestro desde preescolar y primaria hasta los niveles superiores. De aquí que hay 


\section{Trabalhonecessário}

Issn: 1808 - 799X

ano $10, \mathrm{n}=15-2012$

una demanda real de fuerza de trabajo calificada para efectuar la actividad de la enseñanza en particular, lo que implica que ésta tiene un valor de uso, y es necesaria para el proceso de producción capitalista. Sobre todo cuando los procesos de producción se hacen más complejos y requieren un trabajador flexible. Martínez Bonafé continua diciendo que

(...) el proceso de producción de la fuerza de trabajo -la incorporación de valor- está absolutamente condicionado por el objeto de su actividad. Es decir, que esa mercancía vale en la medida en que el mercado mantenga demanda de ella. Si la "cultura" [sic] que se ha incorporado a la energía vital -calificación de la mercancía- no tiene valor de uso para el capital social -[es] porque no responde a otras necesidades e intereses- [por lo tanto] pierde el valor de cambio para su vendedor. Así el valor de uso de la fuerza de trabajo se identifica directamente con la calificación profesional (...). ${ }^{25}$

Para que se contrate a la fuerza de trabajo docente, requiere cubrir las expectativas y lineamientos que demande el mercado (monopolizado por el Estado desde el periodo feudal), es decir, la calificación requerida.

En esta forma, la fuerza de trabajo del docente como mercancía tiene un valor de uso y un valor de cambio; el primero, es la producción de un conocimiento especializado que no es reconocido como trabajo inmediato que hace en la escuela; efectuar diversas actividades en la escuela que van desde la participación en el proceso de enseñanza-aprendizaje de los niños hasta la realización de actividades de organización y gestión escolar, más aún actualmente está desarrollando competencias en el niño para la producción de futuros conocimientos trasmitidos; el último, referido como valor de cambio, se traduce en una remuneración salarial, por lo tanto, el trabajo docente como mercancía (...) 


\section{Trabalhonecessário}

Issn: 1808 - 799X

ano 10, no $15-2012$

está regulado por la totalidad de trabajo socialmente necesarios para producir esa fuerza de trabajo, de modo que muestre valor de uso para su comprador (...). ${ }^{26}$ Esta actividad laboral comúnmente llamada trabajo docente a nivel primaria, añade valor (en tanto que el docente pone en movimiento sus facultades físicas y mentales, ejerce su fuerza de trabajo, con la cual efectúa un producto que tiene una utilidad social, en este caso el produce mercancía fuerza de trabajo más calificada a cambio de un salario) y contribuye también al proceso de valorización y realización del capital.

Esta posición introduce a una discusión (cuestión que Salinas, Carlos Imaz y Martínez Bonafé no declaran), porque en la obra citada de Marx, parece entenderse explícitamente por trabajo productivo, aquella actividad que produce plusvalor (ganancia) de manera directa, pero en forma explícita considera que el trabajo productivo es el que contribuye al proceso de valorización de capital y es aquí donde ubicamos al trabajo docente. Plantea que la educación en el capital era importante, y lo socializó la escuela porque se trataba de educar para el plustrabajo. A lo que Mario Alighiero menciona que (...) existe una profunda valoración crítica de lo que viene reconocida como la función civilizadora del capital. Tal es considerada por Marx lo que podríamos llamar la "pedagogía social del capital", o sea la acción histórica desempeñada por él en la fábrica para disciplinar el trabajo e incluso para educar para el plustrabajo (...). ${ }^{27}$ Esto señala que en el capital se trata de educar para incrementar la ganancia de la burguesía ¿qué nos dice la teoría del capital humano?, y complementa esta cita extraída de Marx diciendo que en el marco histórico social de 1866 se buscaba la unidad entre 


\section{Trabalhonecessário}

Issn: 1808 - 799X

ano $10, \mathrm{n}=15-2012$

el trabajo manual e intelectual, en este sentido la educación, se entiende (...) como una educación física, mental y educación tecnológica (....). ${ }^{28}$

Porque la educación se encuentra naturalmente ligada con el mercado de la fuerza de trabajo a través del proceso de certificación y directamente en el descubrimiento de conocimiento para los pequeños, y la formación de sus habilidades y saberes, que les posibilitaran incrementar la productividad del trabajo, lo cual contribuye claramente a la producción de plusvalor. De ahí la importancia que actualmente se le da a la propuesta sobre el "modelo de competencias", en la escuela primaria.

De tal forma que, para que el trabajo sea productivo, no basta que sea una labor directamente inserta en el proceso de producción de mercancías o la acumulación de capital, o bien ser un trabajo asalariado; sino que es indispensable que el trabajo sea un factor del capital, esto se traduce en que

(...) la capacidad laboral y su trabajo se incorporan directamente como factores vivientes al proceso de producción del capital, se convierte en una de sus componentes, y precisamente en la componente variable, que no sólo en parte conserva y en parte reproduce los valores adelantados en calidad de capital, sino que al mismo tiempo los aumenta y en consecuencia, gracias tan sólo a la creación de plusvalía, los transforma en valores que se valorizan a sí mismos, en capital. Este trabajo se objetiva directamente en el curso del proceso de producción, como magnitud de valor fluida (...). ${ }^{29}$

Este proceso de valorización de capital, donde la producción de mercancía lleva al proceso de acumulación de capital, una vez que aquellas se realizan (venden), permiten así emprender nuevos procesos de producción y/o valorización.

Con evidencia que la actividad de la enseñanza es un trabajo productivo que participa indirectamente y/o incide en la producción de mercancía, al igual que los medios de producción, posibilitando la valorización de capital, en el sentido de 


\section{Trabalhonecessário}

Issn: 1808 - 799X

ano $10, \mathrm{n}=15-2012$

utilidad para el proceso de producción y reproducción del capital, aunque no produzca mercancías tangibles. De acuerdo al esquema de la producción capitalista, las mercancías se componen de dos elementos: fuerza de trabajo e medios de producción. Por otra parte, hay que considerar al maestro como trabajador asalariado (su trabajo vivo es vendido como una mercancía más para el capital, con la única especificación de que está especializada) está logrando del mismo modo la valorización del capital porque a través de su labor se posibilita la reproducción ideológica, cultural, política y económica de la sociedad en su conjunto.

Marx llama al trabajo de la enseñanza como una forma en transición, porque apenas se subsume formalmente en capital, y expone (...) un maestro de escuela que es contratado con otros para valorizar mediante su trabajo el dinero del empresario (...) de la institución que trafica con el conocimiento, (...) es un trabajador productivo (....). ${ }^{30}$ Es aquí donde se reflexiona: ¿es posible concebir el producto del trabajo docente, ya sea de una institución pública o privada, como una actividad que no tuviese nada que ver con la demanda de calificación, certificación y evaluación de la formación de la fuerza de trabajo que demanda el mercado o bien directamente la producción capitalista?

Para el propio Marx, el trabajo productivo es aquel (...) que valoriza directamente al capital, o que produce plusvalía, o sea que se realiza (...) en una plusvalía (...) representada por un plusproducto; (...) esto es [que se realiza] en un incremento excedentario de mercancía (...). ${ }^{31}$ Esto permite afirmar que el trabajo docente es productivo porque posibilita la valorización del capital, 


\section{Trabalhonecessário}

Issn: 1808 - 799X

ano $10, \mathrm{n}=15-2012$

independientemente de que produzca directa-mente o no plusvalor. Al respecto se requiere de otra cita de Marx, donde exhorta a percatarnos de la confusión en la que se puede generar si no existe una comprensión clara y precisa del problema: Sólo la estrechez mental burguesa, tiene la forma capitalista de producción por la forma absoluta, y en consecuencia, por la única forma natural de la producción, puede confundir la cuestión qué es trabajo productivo y trabajador productivo desde el punto de vista del capital, con la cuestión qué es trabajo productivo en general, contentándose así con la respuesta tautológica que es productivo todo trabajo que produce, en general, o que redunda en producto, o en algún valor de uso cualquiera, resumiendo: en un resultado(...). ${ }^{32}$

La valorización de capital y el trabajo productivo se determinan socialmente. El trabajo que implica una actividad generadora de valor, que valoriza al capital, hace entender que cada trabajador es un eslabón del trabajo colectivo, es indiferente la función que realice el trabajador, ya sea que esté más próxima o más distante del trabajo manual directo. Es productivo el trabajo que contribuye a la creación de nuevos valores.

Así, el trabajo docente a nivel de primaria con su actividad, califica mano de obra para la industria o de futuras generaciones docentes, lo que permitirá una mayor producción de mercancías, aquí el conocimiento puede significar un incremento en el desarrollo de las fuerzas productivas y con esto una mayor extracción de plusvalía relativa a la que Marx considera

(...) no es el obrero individual sino cada vez más una capacidad de trabajo socialmente combinada, lo que se convierte en el agente real de proceso laboral en su conjunto, $y$ como las diversas capacidades de trabajo que cooperan y forman la máquina productiva total participan de manera muy diferente en el proceso inmediato de la formación de mercancías o mejor aquí de productos -éste trabaja más con las manos, aquel más con 


\section{Trabalhonecessário}

Issn: 1808 - 799X

ano $10, \mathrm{n}=15-2012$

la cabeza, el uno como director (...) ingeniero, (...) técnico, etc., (...) el otro como capataz (...) el de más allá como obrero manual directo o como simple peón- tenemos que más y más funciones se incluyen en el concepto inmediato de trabajo productivo y sus agentes de trabajadores productivos directamente explotados por el capital y subordinados en general a su proceso de valorización y de producción(....). ${ }^{33}$

Del párrafo anterior se deriva que el trabajo de la enseñanza es un trabajo productivo y sobre todo que contribuye a la valorización del capital, considerando que por valorización, Marx plantea diversas expresiones para definirlo, entre ellas como un proceso que va más allá de la de formación de valor, esto es (...) al transformar el dinero en mercancías que sirven como materias formadoras de un nuevo producto o como factores del proceso laboral, al incorporar fuerza viva de trabajo a la objetividad muerta de los mismos, el capitalista transforma valor, trabajo pretérito, objetivado, muerto, en capital, en valor que se valoriza así mismo $(\ldots) \cdot{ }^{34}$ Lo que significa que el proceso de valorización no es otra cosa más que la formación de un nuevo valor, sobre el valor existente a lo que Marx llama incorporar fuerza viva de trabajo al trabajo pretérito, el cual se convierte en un factor o elemento que permite la producción de una nueva mercancía, es esto "el valor que se valoriza así mismo"35 lo que implica además, agregar más valor a una mercancía dentro del proceso laboral.

De aquí que el proceso de valorización finalmente es la transformación del dinero en mercancías que contribuirán a la creación de otras mercancías que a su vez ayudarán a incrementar el capital; pero este proceso de incremento de valor ocurre en la fase de producción y no en la de la circulación de mercancías, pues es en este último en el que se realizan las mercancías, es decir, se venden, se 


\section{Trabalhonecessário}

Issn: 1808 - 799X

ano 10, no $15-2012$

hace realidad el valor agregado en la fase anterior. El valor es trabajo social, generalmente materializado en mercancías o valores de uso, en los que subyace un trabajo abstracto, el gasto de energía cerebral, nerviosa y muscular, un trabajo en un sentido universal, genera un valor social que es el tiempo de trabajo social requerido para la producción.

En este sentido, Marx plantea que la forma general de expresar el valor se manifiesta en (...) los productos del trabajo como simple gelatina de trabajo humano indiferenciado, deja de ver su propia estructura que es la expresión social del mundo de las mercancías. Hace visible, de este modo, que dentro de ese mundo el carácter humano general del trabajo constituye su carácter específicamente social (....). ${ }^{36}$

Una vez expuestas las herramientas teóricas que hemos recuperado, ponemos a discusión nuestra propuesta que el trabajo de la enseñanza es un trabajo productivo, y que es precisamente desde la perspectiva del proceso de valorización de capital que podemos plantear que la fuerza de trabajo del maestro puede ser vista como una mercancía más dentro del proceso de producción capitalista, aunque por el fetichismo existente en este proceso de acumulación de capital, impide ver el origen del valor de las mercancías y de su propia estructura en la que la fuerza de trabajo para el capital realmente es una mercancía más, dejando de lado su carácter humano y social del trabajo. Sobre todo en el caso del trabajo de enseñanza, se reconoce más su papel social que su carácter productivo en tanto que éste genera un conocimiento, convirtiéndose en una especie de medio de producción que posibilita la fabricación de más mercancías. 


\section{Trabalhonecessário}

Issn: 1808 - 799X

ano $10, \mathrm{n}=15-2012$

Asimismo, el trabajo de la enseñanza tiene un valor de uso y un valor de cambio. De tal forma que lo que produce el maestro a modo de valor de uso es una mercancía intangible, llamada conocimiento, formación, calificación de la fuerza de trabajo (a cambio de un salario, como valor de cambio), cuya demanda se incrementa con el desarrollo de las fuerzas productivas, y contribuye al proceso de valorización de capital; porque en la medida en que avanza el desarrollo capitalista de producción, se requiere más de mano de obra calificada para sostener dicho desarrollo. Es así como podemos ver que el trabajo de la enseñanza es un trabajo productivo que incide en el proceso de valorización de capital.

Prueba de esto es la importancia que asumen los medios masivos de comunicación e innovación tecnológica, como una mercancía más dentro del sistema capitalista, quienes en los siglos XIX y XX no tenían la trascendencia que tienen actualmente en el sector industrial y financiero. En nuestros días la tecnología de la informática y las comunicaciones son vitales para el proceso de producción capitalista, y la educación en este esquema juega un papel fundamental como un instrumento que posibilita la realización de las mercancías materiales e inmateriales y además que permiten la recalificación de la fuerza de trabajo para su uso (mano de obra calificada) y con esto se favorece el incremento en la producción y circulación de mercancías, valores de uso, que actualmente son tanto tangibles como intangibles.

Recordemos que para Marx, la mercancía está constituida por la existencia de los medios de producción y de la fuerza de trabajo, esta última es tan importante como la primera, es por lo tanto para que se dé la producción de mercancías en el sistema capitalista, de aquí que se requiere desde los 


\section{Trabalhonecessário}

Issn: 1808 - 799X

ano 10, no $15-2012$

conocimientos más elementales (en ramas de la industria menos desarrolladas como cerámica, mueblería), hasta de los conocimientos más sofisticados (como sucede con ramas de la industria, como la petroquímica, y las mismas telecomunicaciones generalmente ubicadas en el sector servicios), para dar continuidad al proceso de reproducción capitalista e incluso así como existen mercancía intangibles, también hay elementos que intervienen en la producción de mercancías que son de carácter subjetivo, tal es la naturaleza del trabajo docente y por lo tanto no es simplemente un trabajo de servicio e improductivo.

\section{Conclusiones}

Hemos expuesto a lo largo de este ensayo que nuestra propuesta sostiene que el trabajo productivo emana directamente de las relaciones sociales de producción, es decir, subyace en esta proposición una lógica de trabajo abstracto, porque no todo trabajo necesariamente está vinculado a la producción material o a una condición de tipo tecnológico, aunque generalmente el trabajo productivo se percibe en el proceso de producción, sin embargo en el desarrollo mismo del trabajo también está en la sociedad civil y requiere para su sobrevivencia de la intermediación del Estado burgués.

Desde el inicio del presente ensayo destacamos que nuestro planteamiento teórico se inscribe en una polémica inacaba, no por ello sin fundamentación teórica, sino que consideramos que hemos argumentado teóricamente, haciendo alusión directamente a las fuentes marxistas, y hemos utilizado esta teoría como una herramienta que nos permita explicar nuestra realidad, en este caso, el trabajo docente. $Y$ tratamos de no caer en interpretaciones mecanicistas y dogmáticas de la teoría marxista. 


\section{Trabalhonecessário}

Issn: 1808 - 799X

ano $10, \mathrm{n}=15-2012$

Si bien en el presente ensayo no presentamos un análisis específico sobre nuestra interpretación del trabajo docente en México (esto sería objeto de otro ensayo) a la luz de la teoría del valor trabajo, queremos mencionar que en los últimos diez años se está experimentando una mayor intensificación del trabajo, una mayor diversificación de tareas, y exigencias en la ejecución de actividades que se ajusten a las actuales exigencias del discurso de la modernización educativa, lo que está implicando para los profesores un mayor desgaste físico y mental sin que se otorgue al docente una mayor remuneración salarial, además que los docentes también han tenido que invertir tiempo y dinero para su actualización, para calificar ante las nuevas exigencias laborales, en detrimento de su salud y calidad de vida.

La importancia del trabajo docente desde la perspectiva de la teoría del valor trabajo, implica considerarlo como un trabajo que incide en el proceso de producción capitalista, agregando valor por medio de la formación, capacitación, desarrollo de habilidades, destrezas (ahora llamadas competencias con el discurso de la modernización educativa) en la mano de obra para el mercado de trabajo (trabajo que puede estar vinculado directa e indirectamente en la producción de mercancías), el cual es vital en el desarrollo capitalista. Y también el trabajo docente implica el consumo de trabajo humano, llamado por Marx fuerza de trabajo que implica una perspectiva social que nos permite ver la inexistencia del trabajo individual y la trascendencia del trabajo como la existencia del trabajo como un colectivo social, en el que esta inserta la tarea docente.

Así, el trabajo del maestro no es un simple trabajo, o una labor entre muchas otras existentes en el mercado laboral, o un trabajo social o un trabajo burocrático, técnico, y exclusivo del Estado, etc. El trabajo docente es una 


\section{Trabalhonecessário}

Issn: 1808 - 799X

ano 10, no $15-2012$

actividad profesional, que requirió de una formación y conocimiento especializado, esto implica retomar lo expuesto por Batallan, quien argumenta que las concepciones efectuadas en relación al trabajo docente se asocian al desarrollo de la subjetividad específica en relación al trabajo y a lo que nosotros añadimos, a la forma como se ha desarrollado socialmente el trabajo. (...)[En] nuestra sociedad sigue siendo pertinente la clasificación del trabajo productivo e improductivo [para la reproducción de capital](...) ese carácter (...) está definido por la índole de las relaciones sociales en las que se desarrolla (...), [subrayado propio] ${ }^{37}$, en la que se conceptualiza como un simple empleado público más, la de un trabajador de servicios, y la de un representante del Estado que efectúa las políticas educativas elaboradas por éste. Pero bajo esta mirada corremos el riesgo de quedar atrapados en la vieja discusión un tanto dogmática debido a la clasificación del trabajo productivo e improductivo y por tanto el trabajo docente e improductivo, etc. $Y$ no se hace ningún aporte al respecto y menos aun se destaca el sentido del trabajo docente para el capital.

Por otra parte, afirmamos que desde la mirada de la teoría del valor trabajo, el trabajo docente tiene un carácter objetivo en tanto que añade valor y contribuye al proceso de valorización de capital. Es un trabajo subjetivo en tanto que es necesario al proceso de reproducción de capital en general y está regulado por el Estado, el cual a su vez lo utiliza como un recurso para preservar su legitimidad política, salvaguardar estabilidad social, y las tradiciones culturales, etcétera.

Entre mayor calificación tenga una mano de obra para realizar una actividad laboral, mejores condiciones tendrá para competir en el mercado; esto implica también que la fuerza de trabajo ha efectuado ciertos gastos para formación, por 


\section{Trabalhonecessário}

Issn: 1808 - 799X

ano 10, no $15-2012$

lo cual su costo en el mercado será mayor que el de la mano de obra masa y estará en condiciones de efectuar un trabajo superior y elaborar valores de mayores costos dentro del mercado.

El producto del trabajo docente aparece en la sociedad como una mercancía intangible, a la que hemos llamado conocimiento, pero que tiene por resultado la creación de un valor adicional, que permitirá efectuar un trabajo especializado, con la posibilidad de obtener una mayor producción de mercancías, o bien, de obtener mercancías superiores. De tal forma que lo que produce el maestro a modo de valor de uso es una mercancía intangible, llamada conocimiento, formación, calificación de la fuerza de trabajo, cuya demanda se incrementa con el desarrollo de las fuerzas productivas, y contribuye al proceso de valorización de capital; porque en la medida en que avanza el desarrollo capitalista de producción, se requiere más de mano de obra calificada para sostener dicho desarrollo. Esto nos permite concluir por el momento en este ensayo, planteando que el trabajo de la enseñanza es un trabajo productivo que incide en el proceso de valorización de capital y que esto es demostrado por el desarrollo mismo de las fuerzas productivas que en las actuales condiciones de internacionalización de la economía capitalista en el que han avanzado significativamente la producción de mercancías intangibles como las diversas técnicas de comunicación, entre otros..., se requiere cada vez más mano de obra calificada que responda a la demanda de trabajo. 


\section{Trabalhonecessário}

Issn: $1808-799 X$

ano 10, no $15-2012$

\section{Citas.}

${ }^{1}$ DE LA GARZA, Enrique. El Tratado Latinoamericano de Sociología del Trabajo.

p. 17.

${ }^{2}$ FRIEDMANN, Georges y Naville. Tratado de Sociología del Trabajo. p. 15.

${ }^{3}$ MARTÍNEZ Bonafé, Jaume. Trabajar en la Escuela, (Profesorado y sus

Reformas en el Umbral Siglo XXI). p.87.

${ }^{4}$ ibid. p. 26.

${ }^{5}$ MARX, Karl. El Capital. (El Proceso de Producción del Capital). Tomo I. Vol. 2.

p. 617.

${ }^{6}$ ibid. p. 380.

7 idem.

8 ibid. ps. $381-382$.

9 ibid. p. 379.

10 ibid. p. 617

11 ibid. p. 383.

${ }^{12}$ No debe olvidarse que es la disociación del productor de sus medios de producción, lo que lo obliga a vender su fuerza de trabajo.

${ }^{13}$ MARTÍNEZ Bonafé. op. cit. p. 20.

${ }^{14}$ CHOMSKY, Noam y Heinz Dieterich. .La Sociedad Global. Educación, Mercado y Democracia. p. 116.

${ }^{15}$ De acuerdo a lo expuesto por Marx, la "teoría del valor" Tomo I, Sección Primera del Capital.

${ }^{16}$ MARTÍNEZ Bonafé, Jaume. op. cit. p.21.

${ }^{17}$ NEFFA, Julio César. Proceso de Trabajo, División del Trabajo y Nuevas Formas de Organización del Trabajo. p. 29. 


\section{Trabalhonecessário}

Issn: 1808 - 799X

ano 10, no $15-2012$

${ }^{18}$ Existen otras actividades como las familiares, las sociales, las religiosas y de recreación, que se consideran improductivas, pero gracias a ellas se puede garantizar la reproducción de la fuerza de trabajo y con esto, la existencia misma de la producción capitalista.

${ }^{19}$ Ver SILVESTRE Méndez, José. Problemas Económicos de México.

20 MARTÍNEZ, Jaume. Trabajar en la Escuela. FRIGOTTO, Gaudencio. La productividad de la escuela productiva. Un (re)examen de las relaciones entre la educación y la estructura económico- social capitalista. SMYTH, John. Alastair Dow Robert, Robert Hattam, Alan Reid y Geoffrey Shackloch. "Towards a labour process theory of teacher's work". En Teacher's work in a globalizing economy y el libro de SALINAS y Carlos Imaz. Maestros y Estado (Estudio de las Luchas Magisteriales 1979-1982). En esta perspectiva, se encontraron reflexiones de Martínez Bonafé (en su capítulo "Notas para una Economía Política del Trabajo Docente"), y la propuesta de Carlos Imaz (en el capítulo "Proceso de Trabajo Docente y las condiciones de venta de la fuerza de trabajo del maestro").

21 ibid. p. 32.

22 ibid. ps. 15 y 22.

23 ibid. p. 21.

24 ibid. p. 22.

${ }^{25}$ MARTíNEZ Bonafé. op. cit. p. 25. El maestro de primaria es clave en el proceso educativo y en el proceso de formación de un humano, además produce un conocimiento especializado en el alumno porque éste (su objeto de trabajo) se encuentra en etapa inicial de aprendizaje elemental. Sin embargo, para que el niño aprenda, el profesor requiere de experiencia y capacitación, el profesor debe estar preparado para desarrollar y proporcionar su trabajo. Por otra parte, la práctica 


\section{Trabalhonecessário}

Issn: $1808-799 X$

ano 10, no $15-2012$

cotidiana hace que el profesor adquiera una experiencia aunada a habilidades que se transforman en extra-capacidades peculiares (individualizadas) que sólo la misma práctica le otorga en el momento en que se encuentra enseñando; además de una calificación especializada sobre su propio trabajo, que no son reconocidas como una capacidad generadora y transformadora de conocimientos como el que proporciona el sector productivo cuando transforma la naturaleza. En síntesis, el profesor transforma al niño y se transforma a sí mismo, aunque generalmente se habla desde el ángulo psicopedagógico como el proceso de enseñanzaaprendizaje.

${ }^{26}$ ALIGHIERO Manacorda, Mario. Historia de la Educación. p. 464.

27 ibid. p. 465.

${ }^{28}$ MARX, Karl. El Capital. Libro I Capítulo VI (Inédito). p. 80.

${ }^{29}$ ibid. p. 84-85.

30 ibid. p. 77.

31 ibid. p. 78.

32 bid. p. 79.

${ }^{33}$ MARX. El Capital. Tomo I, Vol. I, Libro Primero: El Proceso de Producción de

Capital. Capítulo V "Proceso de Trabajo y Proceso de Valorización”. p. 236. ${ }^{34}$ idem.

${ }^{35}$ MARX, Karl. "El Proceso de Producción del Capital". En El Capital. Tomo I Vol. 1 Libro Primero: El Proceso de Producción de Capital. Capítulo I. p. 82.

${ }^{36}$ BATALLAN, y García. "Maestros, la especificidad del trabajo docente y la transformación escolar" en ALLIUD, Andrea. Formación, Práctica y Transformación Escolar. p. 225. 


\section{Trabalhonecessário}

Issn: 1808 - 799X

ano 10, no $15-2012$

\section{Bibliografía.}

AGUILAR, C. El trabajo de los maestros. Una construcción cotidiana. México DIE CINVESTAV-IPN.1986

ALIGHIERO M, Mario. Historia de la educación del 1500 a nuestros días. Siglo XXI. México. 1999.

BATALLÁN, G. y Fernando García. "La especificidad del trabajo docente y la transformación escolar". En ALLIUD, Andrea (coord). Maestros, formación, práctica y transformación escolar. Buenos Aires, Miño y Dávila 1998.

CASTREJÓN S. Impacto de la modernización educativa en las condiciones del trabajo de los profesores de educación primaria. Estudio de caso. Tesis de maestría UPN. México. México, 2004.

CHOMSKY, N. y H. Dieterich. La Sociedad Global. Educación, Mercado y Democracia. Introducción de Luís Javier Garrido. $2^{\underline{a}}$ ed. México. Joaquín Mortiz (Contrapuntos), 2002.

DE LA GARZA E. et al. Tratado latinoamericano de sociología del trabajo. México COLMEX-UAM, Fondo de Cultura Económica., 2000.

DIKER, G. y Terigi. La formación de maestros y profesores: hoja de ruta. México, Paidós, 1997. 


\section{Trabalhonecessário}

Issn: $1808-799 X$

ano 10, no $15-2012$

FRIEDMANN y N. Georges. Tratado de la sociología del trabajo. México, Vol I. Fondo de Cultura Económica 1985.

FRIGOTTO, G. La productividad de la escuela productiva. Un (re)examen de las relaciones entre la educación y la estructura económico- social capitalista. España, Miño y Dávila Editores. 1998.

HOBSBAWN, E. et al. El Pensamiento Revolucionario de Gramsci. México, Benemérita Universidad Autónoma de Puebla. 1978.

IANNI, O. La era del globalismo. México, Siglo XXI. 2001.

MARTÍNEZ B. J. Trabajar en la escuela. (Profesorado y reformas en el umbral del siglo XXI). España, Miño y Dávila Editores. 1998.

MARTíNEZ, D. El Riesgo de enseñar. México, Fundación SNTE para la Cultura del Maestro Mexicano. 1992.

MARX, K. El Capital. Tomo I/ Vol. I. Tomo primero. (Proceso de producción de capital) Cap. V: "proceso de trabajo y proceso de valorización". México, Siglo XXI. 1990.

MARX, K. El Capital. (El proceso de producción del capital) Tomo I/ Vol. 2. México, Siglo XXI. 1990. 


\section{Trabalhonecessário}

Issn: $1808-799 X$

ano 10, no $15-2012$

MARX, K. El Capital. Libro I Capítulo VI (Inédito). 9ª ed., México, Siglo XXI. 1981.

MEDÁ, D. El trabajo (Un valor en peligro de extinción). España, Gedisa. 1998.

NEFFA, J. C. Proceso de trabajo y división del trabajo, división del trabajo y nuevas formas de organización del trabajo. México, Instituto Nacional de Estudios del Trabajo. 1982.

SALINAS, S. y C. Imaz. "Descripción del Proceso de Trabajo Docente", en Maestros y Estado. Vol. I. México, s.f.

SALINAS S. y C. Imaz. "Estudio de las Luchas Magisteriales 1979-1982", en Maestros y Estado México, s.f.

SILVESTRE M. J. Problemas Económicos de México. México, MCGRAW-HILL Interamericana, 2008

SMYTH, J. Alastair Dow Robert, Robert Hattam, Alan Reid y Geoffrey Shackloch. "Towards a labour process theory of teacher's work". En Teacher's work in a globalizing economy. Tr. Jorge Martínez Zendejas, del capítulo que se utilizó) Estados Unidos, Routledge. 1999.

TELLO, Marcos. Trabajo docente, lucha sindical y democracia en las movilizaciones magisteriales. Tesis de licenciatura. Escuela Nacional de Antropología e Historia. México, 1997. 